\title{
Identification and Ranking the Current Barriers in National Tax System (The Comprehensive Tax Plan)
}

\author{
Majid Shahmoradi $^{1} \&$ Hasan Atri. ${ }^{2}$ \\ ${ }^{1}$ Master's Student in State Management Majoring on Finance, Science and Research University Branch of \\ Islamic Azad University System in Iran, Tehran, Hesarak \\ ${ }^{2}$ Phd, Assistant professor, Science and Research University Branch of Islamic Azad University System in Iran, \\ Tehran, Hesarak \\ Correspondence: Hasan Atri., Science and Research University Branch of Islamic Azad University System in \\ Iran, Tehran, Hesarak. E-mail: majid6531@gmail.com, hasanatri@gmail.com
}

Received: January 4, 2016

Accepted: February 16, 2017

Online Published: May 14, 2017

doi:10.5539/mas.v11n6p82

URL: https://doi.org/10.5539/mas.v11n6p82

\begin{abstract}
Tis study aims to identify and rank the obstacles found in the change of country tax system (tax comprehensive plan). In the first chapter, some questions have been raised and along them, some hypotheses are considered.

The general questions of this study are: do environmental obstacles influence on successful implementing of tax comprehensive plan? Do organizational obstacles influence on successful implementation of tax comprehensive plan? Do behavioral obstacles influence on successful implementation of tax comprehensive plan?

The method of this research is practical by purpose, and it is descriptive by data collection. Statistical population of this study is consisted of all of experts and managers of organization of country tax affairs and based on Cochran formula 106 people of personnel and manager of Tehran tax affairs and personnel in the building of tax comprehensive plan are selected as the sample. Considering the study literature, behavioral obstacles, environmental obstacles and organizational obstacles are evaluated and a questionnaire is designed based on mentioned variables with five scales of Likert with demographic variables. In this study, after preparing the study plan and studying and collecting its theoretic basics, two questionnaires are prepared for identifying and ranking the obstacles for study statistical sample and after distributing and gathering questionnaires, descriptive inferential statistics has been used for data analysis, and nonparametric test is used for hypothesis test. 10 of 13 hypotheses are proved and three of them failed to be proved which the proved results of this study are consistent with those of previous research ( about unproved hypotheses, they weren't consistent, therefore, they can be examined for future research), then, through Friedman test,

they are ranked as follows: 1- resistance of personnel against the change, 2-cultural factor, 3- behavioral factor, 4- lack professional workforce, 5- environmental factor 6- technological factor , 7- organizational factor, 8- lack of managers' support, 9- technological factors (organizational), 10- domestic policy. Conclusion: considering the impact of cultural factor on the implementation of plan, it is recommended to include some pedagogic materials in textbooks of students and to make teaser ads and make animation and accomplishing education and expressing the importance of implementing the plan for general public, in order to promote a culture in this regard for all ages.

Suggestions: In the current state budget and tax Civil Affairs with support at work and Parliament also about requiring all go vernment agencies and non-go vernmental entities and financial and non-financial entities to submit information and supervision act.
\end{abstract}

Keywords: ranking, change plan, tax system.

\section{Introduction}

Considering its triple functions, tax system has a key role in the economic and social systems of any country. Based on this fact and considering the effect of tax system on other economic sections and related challenges along with their expansive interaction with community as axes of economic change. The reformation of this system have implemented in three main axes including the reformation of tax rules and regulations, the implementation of comprehensive tax plan, and the complete establishment of the vat system. The 
comprehensive tax information system is considered as the heart and main part of tax system in every country while any tax system's success depends on the amount of expansion of tax information system.

A well-planned and well-designed tax information system is an effective factor in the amelioration of detection and taking tax, decreasing tax fraud, reduction of corruption, elimination of discrimination and increasing efficiency and a factor for more precise adjustment of the budget.

In our country, the lack of a coherent, and harmonious, and mechanized tax information system has caused a gap between the potential capacity of the economic tax and its actual capacity and staying deprived of higher tax revenues, while receipt of the very amount of tax rate has astronomic costs in all dimensions including material, social and economic costs for the country. Thus, the tax comprehensive tax plan took the attention of decision-making authorities of economy (Barati et al, 1393).

The comprehensive tax plan is a national important plan which if gets executed it can improve different methods of taxation, the growth of tax revenues and prevent tax fraud. In this regard, the Taxation Affairs Organization believes that there is no other option rather than the comprehensive tax plan for financing the current government expenses. This plan is also very justified economically because it has high rate of investment return being for less than a year.

One of the obstacles against the plan execution is the tax fraud of guilds and business owners as there is not a clear information system in this regard and it is based on declaration forms that they fill themselves which can amalgamate tax fraud.

Considering the problems above, the general goals of the Comprehensive Tax Plan can be mentioned in the following categories which are connected like a cycle and realizing a goal can be effective in realizing other goals (Kalantari, et al, 1392):

Increasing tax revenues via preventing tax frauds and reduction of the volume of the underground economy, reduction of social, operational, and executive expenses via mechanization of operation and the optimization of the processes, increasing the beneficiary's content via improving services to the individuals and making their interaction with organizations easy, respect to them and restoring tax justice, improving the level of information dominance of the tax system through the use of all information sources manufacturer Information, exchanging information for efficient and safe information management, increasing the level of tax compliance through improved detection methods, reduction of corruption by minimizing the relationship between taxpayers and tax officers, mproving the level of information dominance of the tax system through the use of all information of Information sources.

For implementing the comprehensive tax plan, identifying and ranking the barriers of the project is necessary more than ever.

The literature on the comprehensive tax system in the country is scares and, based on the researches, there is no research that has examined the comprehensive tax system and its ranking via Fridman approach.

\section{Research Method}

This research is applicable in terms of goal and descriptive in terms of data gathering. This research is, also, cross sectional in terms of time. After forming the plan of research and studying and collecting the theoretical foundations, the present study provides 2 questionnaires to detect and rank obstacles for statistical samples. After the distribution and collecting questionnaires and based on the analysis of the resulting data, the conclusions and suggestions are presented. This paper studies Taxation Affairs Organization .The study lasted from May to January 1394 and its subject involves identifying and ranking the barriers in the development of the country's tax system.

To gather the data of this research, two methods are used:

1. Biblical method in gathering the secondary data: referring to different libraries from different universities and institutes, data banks, the internet and the Iranian Center for Information and Documentation, the needed data are gathered.

2. The field method in gathering the primary data: In this method, questionnaire and sampling and statistical study of population for extracting data are used. In planning the questionnaire, the Likert five option spectrum is utilized. The population encompasses all experts and managers of the Taxation Affairs Organization.

In this study, descriptive statistics are used to determine tables, graphs and central indicators to describe the data using SPSS and Excel software. The following inferential statistics are also used:

Cronbach's alpha test to determine the reliability, Shapiro-Wilk test (Sig) for the Normal distribution of statistics, 
and T-test or $\mathrm{x} 2$ test to determine the status of each of the variables via SPSS software. The Friedman test is also used for ranking.

\section{Data Analysis}

First Hypothesis: Environmental barriers are effective in successful implementation of comprehensive tax plan.

The high difference between the number of samples in the second group (an average of more than 3 ) relative to the first group (an average of less than 3 ) shows that there is no evidence to reject the hypothesis of effectiveness of environmental obstacles on successful execution of the comprehensive tax plan.

Second hypothesis: Legal factor is effective in successful implementation of comprehensive tax plan.

In this test, with regard to the value of the significance which shows the rejection of the hypothesis, it can be said that according to the respondents, effectiveness of legal factor on successful execution of the comprehensive tax plan is rejected.

Third Hypothesis: Cultural factor is effective in successful implementation of comprehensive tax plan.

The high number of samples in the second group (the average of more than 3) relative to the first group (an average of less than 3) shows that there is no evidence for rejecting the research hypothesis on cultural factor being effective on successful execution of the comprehensive tax plan.

Fourth Hypothesis: Technological factor is effective in successful implementation of comprehensive tax plan.

The high difference between the number of samples in the second group (the average of more than 3 ) relative to the first group (an average of less than 3 ) shows that there is no evidence for rejecting the research hypothesis on technological factor being effective on successful execution of the comprehensive tax plan.

Fifth Hypothesis: Institutional barriers are effective in successful implementation of comprehensive tax plan.

The high difference of the number of samples in the second group (the average of more than 3 ) relative to the first group (an average of less than 3 ) shows that there is no evidence for rejecting the research hypothesis on institutional barriers being effective on successful execution of the comprehensive tax plan.

Sixth Hypothesis: Internal Affairs factor is effective in successful implementation of comprehensive tax plan.

The high difference between the number of samples in the second group (the average of more than 3 ) relative to the first group (an average of less than 3 ) shows that there is no evidence for rejecting the research hypothesis on internal affairs factor being effective on successful execution of the comprehensive tax plan.

Seventh Hypothesis: Tax regulations factor is effective in successful implementation of comprehensive tax plan.

In this test, with regard to the value of the significance which shows the rejection of the hypothesis, it can be said that, according to the respondents, effectiveness of tax rules on successful execution of the comprehensive plan tax is rejected.

Eighth Hypothesis: Technological factor is effective in successful implementation of comprehensive tax plan.

The high difference between the number of samples in the second group (the average of more than 3 ) relative to the first group (an average of less than 3 ) shows that there is no evidence for rejecting the research hypothesis on technological factor being effective on successful execution of the comprehensive tax plan.

Ninth Hypothesis: Structural factor is effective in successful implementation of comprehensive tax plan.

In this test, with regard to the value of the significance which shows the rejection of the hypothesis, it can be said that, according to the respondents, effectiveness of legal factor on successful execution of the comprehensive plan tax is rejected.

Tenth Factor: Behavioral barriers are effective in successful implementation of comprehensive tax plan.

The high difference between the number of samples in the second group (the average of more than 3 ) relative to the first group (an average of less than 3 ) shows that there is no evidence for rejecting the research hypothesis on behavioral barriers being effective on successful execution of the comprehensive tax plan.

Eleventh Hypothesis: The lack of professional work force is effective in successful implementation of comprehensive tax plan.

The high difference between the number of samples in the second group (the average of more than 3) relative to the first group (an average of less than 3 ) shows that there is no evidence for rejecting the research hypothesis on the lack of professional work force factor being effective on successful execution of the comprehensive tax plan. 
Twelfth Factor: The lack of support from the tax senior managers is effective in successful implementation of comprehensive tax plan.

The high difference between the number of samples in the second group (the average of more than 3 ) relative to the first group (an average of less than 3) shows that there is no evidence for rejecting the research hypothesis on The lack of support from the tax senior managers factor being effective on successful execution of the comprehensive tax plan.

Thirteenth Factor: Employees' resistance against change is effective in successful implementation of comprehensive tax plan.

The high difference between the number of samples in the second group (the average of more than 3 ) relative to the first group (an average of less than 3 ) shows that there is no evidence for rejecting the research hypothesis on the resistence of employees against change being effective on successful execution of the comprehensive tax plan.

Ranking Factors:

With regard to the anomaly of distribution of the data and the use of non-parametric tests in raking factors, we used Friedman test the results of which can be seen in what follows:

-Employees' resistance against change

-Cultural factor

-Behavioral Factor

-The shortage of professional work force

-Environmental factor

-Technological Factor (environmental)

-Organizational factor

-The lack of support of managers

-Technological factors (organizational)

-Internal Affairs

As it is shown, the employees' resistance against change has the highest impact and the cultural factor has the highest on the implementation of the comprehensive tax plan.

\section{Comparison and Adaptation of Findings}

In a research, Ghanbari and colleagues (2015) examine barriers to implementation of electronic tax cuts and prioritized these obstacles. The results show that obstacles of electronic implementation of taxation respectively are: environmental, behavioral, and organizational factors. Also, the following two factors of importance that are effective for unsuccessful implementation of include the lack of electronic services in banks as an infrastructure for this system and the lack of legal security in the electronic transactions. The results of the investigation are compatible with the results of the present investigation.

In a research, Barati (1393) examines the electronic tax system and the forthcoming challenges. The results showed: technical and infrastructural variables, social effects, effort expectations, legal issues, effectiveness expectation, access to information, understood risks respectively have more effects on the acceptance of the electronic tax system. The results of the above investigation are compatible with the results of the present investigation.

Asgari and colleagues (1390) have implemented a research on the effect of cultural factors on the efficient implementation of added value taxes in the total of tax reporting culture and thereby increasing tax docility are some of the main concerns of tax managers. Improving tax culture will improve the content of tax managers. The results of the investigation above are compatible with the results of the present investigation.

\section{Conclusion and Suggestion}

Limitations of the Research

Disaffiliation of some managers in the survey units.

As a result of financial and time barriers, we could not use interview to enhance data gathering care.

\section{Result based applicable suggestions}


Considering the effect of cultural factors of plan implementation, it is suggested to include educational texts in school books and making animation and advertising teasers, educating and expressing the value of the plan for the community can lead to promotion of culture in this regard.

With regard to confirmation of the behavioral and resistance to employees against change factors, it is suggested for the government to take a different view in relation to the current expenses of the institute to take care of welfare and life expenses of the employees. With regard to the resolutions of the parliament on cooperation of organizations to link to the Taxation Affairs Organization, financial information of people should be pass legal checks. Meanwhile, by good informing people and education, we can adapt employees to this act.

Considering the fact that the effect of internal affairs factor is approved, it is suggested that the main priority of the authorities and employees is be the whole implementation of the plan. It is suggested for it to orient toward implementation of plan policies.

Considering the fact that the two factors of institutional and technological factors are approved, it is suggested to observe and learn from successful countries to make the grounds ready for the implementation of the plan.

\section{Limitation based suggestions for future researches}

With regard to the importance of the comprehensive cooperation of guilds for doing the plan, it is suggested to do another research to identify and rank effective factors on the encouraging them toward the plan via multi-criteria decision-making technics.

We suggest doing a research on identification of effective factors on application of successful plans resembling this one taking a look at other countries.

\section{References}

A rare honor God and Mary Saif Naraqi and F Shahpourian (1375). A practical guide providing research design, Third Edition, Office of Research and Publications Badr.

Aghazadeh, I., Tahereh, A., \& Mahmoud, B. (1393). Investigate the relationship between corporate income tax policy and foreign direct investment in Iran, the first national economic and practical management approach conference with national approach, Babolsar, a research firm in Torud, north.

Alizadeh, B., \& Ebrahim, H. (1394). The tax increase against West sanctions on Iran, the International Conference on Management, Economics and Financial Systems, Dubai, the company of Pendar Andish Rahpou.

Anbari, M., Bagheri, R., \& Davodi, H. (2013). Survey of Social factors Effective on discontinuation of innovation in rural areas (Case Study: Drip irrigation Technology in Lorestan). Journal of Science and Today's World, 2(5), 451-464.

Anuar, S., \& Othman, R. (2010). Determinants of online tax payment system in Malaysia. International Journal of Public Information Systems, 2010(1), 17-26.

Askari, A. (1392). Analyses of Tax Reform: Challenges, applications and operation of the tax system, fiscal policy and economic. Journal of the Government's Economic Record, 2, 85-120.

Azar, A. (1383). Statistics and its application in management, Samt publishing, Tehran, Third Edition.

Barati, A. (1393). The financial system and challenges facing the electronics case study: Tax payers in Kermanshah province, the International Conference on Economics, Accounting, Management and Social Sciences, Poland.

Barati, A., Najafi, A., Azizpour, \& Mehdi, S. N. (1393). implementation of electronic tax system, a factor affecting the economy of resistance in case of tax payers Kermanshah province, the International Conference on Economics, Accounting, Management and Social Sciences, Poland.

Davodi, H., Shabanali, F. H., \& Kalantari, K. (2012). An investigation of technology development barriers in Agricultural Science and Technology Parks of Tehran University.

Ghanbari, M., Naserabadi, D., Veisi, F., \& Moezzi, F. (2015). The Electronic Tax in the Tax System of (Case Study of the Tax administration of Kurdistan Province). Journal of Applied Environmental and Biological Sciences, 5(10S), 268-274.

Ghanbari, Mehrdad. and Norollah. Fakuryan (1394). Effect of accounting standards and offer you the cost of goods sold by independent auditors on audit of VAT, the first International Conference on Accounting, Audit Management and Economics, Isfahan, Conference Secretariat. 
Ghasemi ardakani, \& Mohammad, A. H., Sharifabadi, A. M., \& Alireza, N. S. A. (1393). A Model for identifying and ranking the factors for intension identification of factors effective on in using taxpaying machines, the first National Conference of futures research, management and development, Tehran, Iran's new education development center (Metana).

Giesecke, J. A., \& Hoang, N. T. (2010). Modelling value-added tax in the presence of multi-production and differentiated exemptions. Journal of Asian Economics, 21(2), 156-173.

HafzNia, M. R. (1382). An introduction to research method in humanities, Samt publishing, Tehran, Eighth Edition.

Heidarinejad, G., \& Kazemi, A. A. (1391). Structural reform of the tax system of VAT; Challenges and Solutions, First International Conference on Management, Innovation and national production, Qom, Khuzestan province PNU.

International Center of Academic Communication (ICOAC) ،Universitat Autonoma De Barcelona.

Jeyhoon, T. Fawzia, Z. N., \& Zohreh, R. (1394). Exploration of causal relationships between taxes and government expenses in Iranian economy: a multivariate approach, the first International Conference on Accounting, Audit Management and Economics, Isfahan, Conference Secretariat.

Khaki, G. (1382). Methods in Management Research. Center of Scientific Publications of the Islamic Azad University, Tehran, (2nd Ed.).

Knight, J., \& Parivash, J. (1387). Design the appropriate management of VAT in Iran (with emphasis on stakeholder groups. Economic Journal, 8(4), 69 -98.

Koedel, C., Mihaly, K., \& Rockoff, J. (2015). Value-added modeling: A review .Economics of Education Review, 47:180-195.

Lai M., \& Choong, K. (2012) Motivators, Barriers and Concerns in Adoption of Electronic Filing System: Survey Evidence from Malaysian Professional Accountants. American Journal of Applied Sciences, 7(4), 562-567.

Liu, Q., \& Lu, Y. (2015). Firm investment and exporting: Evidence from China's value-added tax reform, Journal of International Economics, In Press, Corrected Proof, Available online 30 July 2015.

Maghsoudi, T., Yazdi, F. K., Joneydi, M. S., Sedighi, N. T., \& Davodi, H. (2013). Sustainability of agricultural water management associations in Iran (Case study of Khuzestan Province). European Journal of Experimental Biology, 3(1), 545-550.

Mahjoub, Behnam, Hadi Rahim-Pour and Mohammad Fadaei (1394). The financial failure of Iran and efficiency of VAT, The International Conference on Management Economics and Social Sciences, Spain.

Masoumi, Shiba and Morteza Yousefi (1393). The impact of the implementation of electronic tax system on the process of providing tax services to taxpayers INTA (Case study: Finance offices in Golestan Province), the first international conference on economics, management, accounting and social sciences , Rasht, Anzali free Zone, collegiate entrepreneurs Company.

Mathani, Mehrdad. (1386), Principles of research in management, publishing Mahdonnabi.

Meshki, Mahdi., Morteza Maryami Yaghoubian and Mehdi Hemmati Asiyabrki (1391). Providing a structural model for electronic tax, tenth National accounting Congress, Tehran, Al-Zahra University.

Ministry of Economic Affairs and Finance, Department of Economic Affairs, briefing paper bill amending the law on direct taxes.

Ministry of Economic Affairs and Finance, Department of Economic Affairs, the backup plan to change the tax system of the country.

Ministry of Economic Affairs and Finance, Department of Economic Affairs (1390), documentation development plan tax system.

Ministry of Economic Affairs and Finance, Department of Financial Supervision and the national treasury, financial status reports state.

Ministry of Economic Affairs and Finance, State Tax Organization (1391), report comprehensive tax plan.

Ministry of Economic Affairs and Finance, State Tax Organization, Direct Tax Law.

Ministry of Economic Affairs and Finance, the State Tax, Value Added Tax Act. 
Momeni, Mansour and Ali Faal Ghaiyoomi (1389). statistical analysis using SPSS, Tehran, Ketab-e-No publishing.

Naderi, Ezatollah, Maryam Saif Naraqi and F Shahpourian (1375). A practical guide providing research design, Third Edition, Badr Research office and Publications.

Nejati, H., \& Mahmoud (1382). analysis of historical identity, historiography and historical sociology Iran: theoretical and methodological considerations, national studies, No. 15.

Pirayesh, R., \& Masoumeh, I. (1394). The increase of the culture of self-reliance in taking tax on value, the first international conference of management and accounting with an approach of value creation, Tehran, Islamic Azad University, Fars Science and Research Institute.

POLICE Behold, M. A. R. theoretical and devoted Faith (1392). A review of the development plan of the tax system, fiscal policy and economic Journal, 1(1), 59-80.

Qaderi, J., \& Izadi, B. (1393). The total tax on foreign savings in the effectiveness of sanctions: the case of Iran, the second international conference on the economy in terms of sanctions, Babolsar, a research firm Torud north

Rasekh, M., Ameneh, A., \& Amir, K. (1393). Examining the economic effects of VAT in Iran, the first national economic conference and practical management approach, Babolsar, a research firm Torud north.

Rostamnejad, C. M., \& Hashemi, A. N. (1393). Examination of the barriers to implementation of VAT law in the province: a case study cities of Sari and Babol, the first national economic and practical management approach conference, Babolsar, a research firm Torud; North.

Sarmad, V., Bazargan, A., \& Hejazi (1383). Research methods in the behavioral sciences; Aghah publishing.

Sarmad, V., Bazargan, A., \& Hejazi (1383). Research methods in the behavioral sciences; Aghah publishing.

Sarookhani, B. (1383). Quantitative methods in social sciences, III, published meeting.

Sarookhani, B. (1383). Quantitative methods in social sciences, III, published meeting.

Sheibani, N., \& Mohammad, N. S. T. (1394). Investigating the factors affecting tax fraud in the Tax Administration of the city of Zahedan, the first International Conference on Accounting, Audit Management and Economics, Isfahan, Conference Secretariat.

Taboli, H., \& Mahmoud, S. (1394). Examination of the relationship between VAT and financial ratios of listed companies in Tehran Stock Exchange, First International Conference on Accounting, Audit Management and Economics, Isfahan, Conference Secretariat.

Talvi, E., \& Végh, C. (2005). Tax base variability and procyclical fiscal policy in developing countries. Journal of Development Economics, 78(1),156-190.

Zhang, Y., \& Huang, J. H. (2015). Cost-based pricing model with value-added tax and corporate income tax for a supply chain network. Applied Mathematical Modelling, 38(1),168-180.

\section{Appendix Indices}

In the Name of God

Respectfully,

The following questionnaire has been prepared in order to use your comments about "identifying barriers in implementing comprehensive tax plan". Considering that your reserved and honest answers are confidential, please carefully select the appropriate options.

Regards.

Gende: Male( ) Female( )

Age: Less than 25( ), 25-35( ), 36-45( ), 46-55( ), more that 55( )

Career.

Education: Diploma and less( ), Associate( ), Bachelor( ), Master's( ), $\mathrm{PhD}($ )

Work experience: Less than 5 years( ), 5-10( ), 11-15( ), 20-16( ), 21-25( ), more than 25( )

\begin{tabular}{|l|l|l|l|l|l|l|l|l|}
\hline Row & Main aspects & factors & questions & Very & low & mediocre & high & Very \\
\hline
\end{tabular}




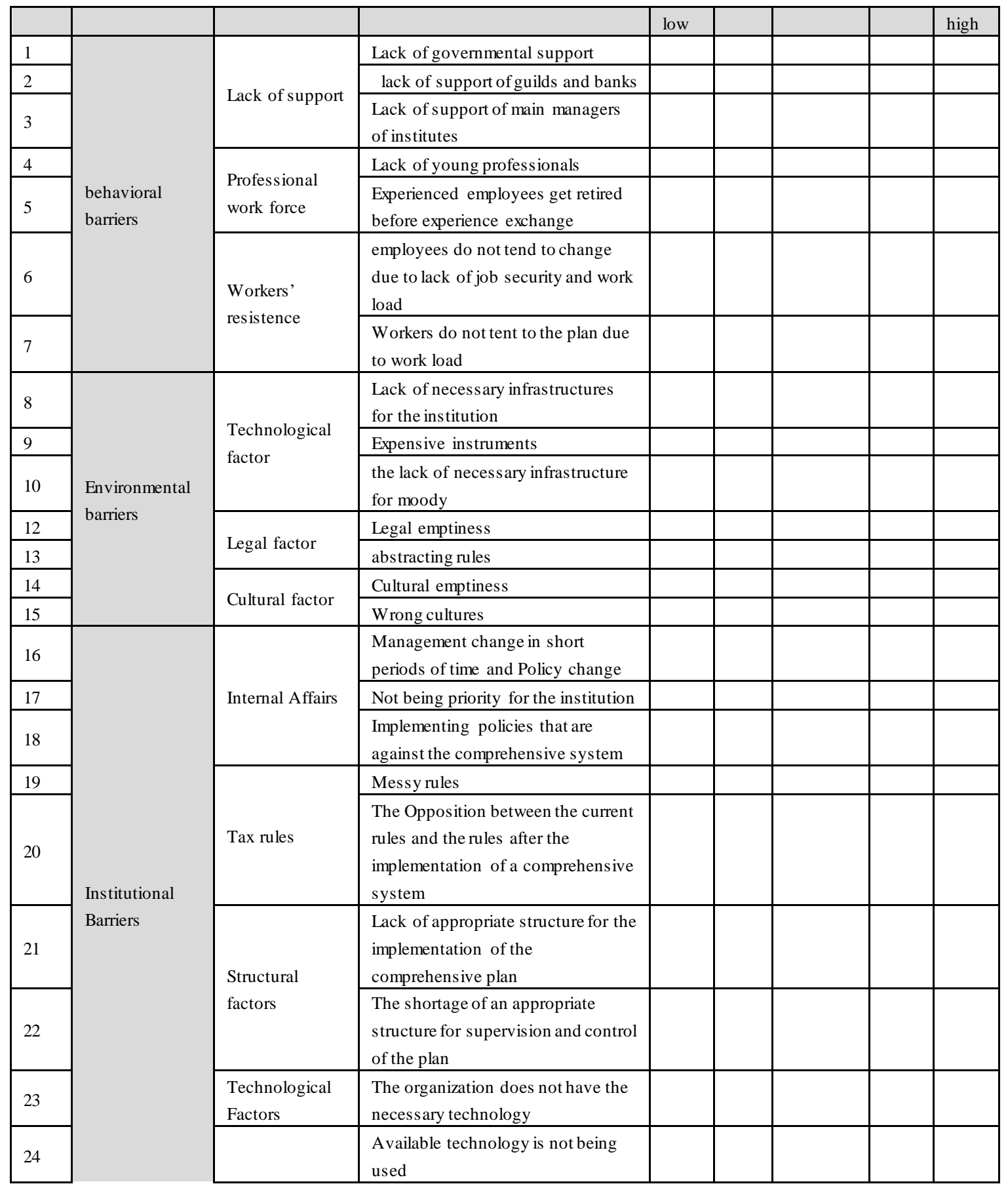

\section{Copyrights}

Copyright for this article is retained by the author(s), with first publication rights granted to the journal.

This is an open-access article distributed under the terms and conditions of the Creative Commons Attribution license (http://creativecommons.org/licenses/by/4.0/). 